\title{
Potential Web Based Cognitive Exercises in Remediation of Mind (ReMind) Programme for Schizophrenia Recovery
}

\author{
P Naniyati Shuib, Mahadir Ahmad, Zubaidah Jamil Osman, Muhammad Najib Mohamad Alwi
}

\begin{abstract}
The use of computerized cognitive exercises is recognized in cognitive remediation (CR) which designed specifically for a rehabilitation purpose in psychiatric illness particularly schizophrenia. Specific criteria of cognitive exercises were analyzed in a need analysis as a potential tool to ameliorate cognitive deficits in the Remediation of Mind (ReMind) programme with targeted processing speed for early intervention that influence cognitive enhancement effects. The existing educational software and commercial web based cognitive training were identified and explored in participants who attended 15 sessions of CR through a focus group discussion for the viability and effectiveness to enhance global cognition performance and functional outcome.
\end{abstract}

Keywords: Computerized cognitive exercise, cognitive remediation, processing speed, schizophrenia..

\section{INTRODUCTION}

Trends in globalization, information technology (IT) encompasses the internet and other computer components become common in delivering knowledge. CR approaches was merely on computerized exercises. Computerized software of cognitive exercises are types of remediation tools, which globally known lead to the effects on cognition, social and symptom reduction. Although this CR mechanism is proven as an evidence-based intervention, the emerging technology reveals some of the breakthrough innovations that are expected to produce more interesting exercises in improving global cognition and psychosocial functioning. Therefore, the other types of web app development were found to be relevant and suitable to be used as part of the platform in learning process as the web based application has demonstrated numerous advantages and portable [1], [2] rather than conventional static web application which came in a CD form and standalone concept which is already outdated in this era despite the undisputable benefits.

Thus, computers can be intimidating as well as inspiring because they can also be challenging [3] for participants who have difficulties with perceptual mechanisms, motor control, visual pursuit and scanning, and educational deficits such as poor reading skills, cognitive rigidity or inflexibility.

Revised Manuscript Received on September 14, 2019.

Naniyati Shuib, Faculty of Health Sciences, Universiti Kebangsaan Malaysia.( Email: nani.shuib@gmail.com)

Mahadir Ahmad, Faculty of Health Sciences, Universiti Kebangsaan Malaysia. Email: mahadir@ukm.edu.my

Zubaidah Jamil Osman, Faculty of Allied Health Sciences, Cyberjaya University College of Medical Sciences, Malaysia. (Email: zujamil@gmail.com)

Muhammad Najib Mohamad Alwi, International Medical School, Management and Science University, Malaysia. (Email: drnajibalwi@gmail.com.)
The Neuropsychological Educational Approach to Remediation (NEAR) relies on computerized exercises that can be delivered as local, hard-drive-based-software or as part of a web-based program that required therapists to choose the computerized exercises to conduct CR to remain relevant and up to date with the latest developments in technology besides its appropriateness for treatment setting [1].

In general, previous studies of $\mathrm{CR}$ demonstrate improvements on attention, memory, problem solving, and social functioning following training [4], [5]. Neuropsychological key dysfunctions were earlier targeted directly such as those of executive function, attention and verbal memory as revealed by the prominent scholars in cognitive remediation including Wykes, Medalia, Vauth, Bell, Bellucci, and van der Gaag and other colleagues with varying success results [6]. Most authors reported some improvement in executive function, including working memory due to training. However, training differences are typically specific to the ability trained, with those individuals trained in attention experiencing gains in attention but not in other domain and vice versa [7].

There is evidence suggested that CR improved cognitive function that lead to social functioning in the context of psychological interventions. However, another concern is the identification of the cognitive domains that need to be targeted to improve functioning [8]. In fact, the largest impairments were found in processing speed (-1.68), reasoning and problem solving (-1.51) and sustained attention (-1.40), while verbal learning and memory (-.79) and visual learning and memory (-.63) were the least deteriorated. The level and severity of these deficits consistent to a meta-analytic study [9] of cognitive impairment in first-episode schizophrenia. It implies a stage of the illness, when test performance has not been influenced by potential medication or chronicity confounders [10] through its hypothesis that deficits in cognition in schizophrenia may be determined by a low processing speed of cognitive performance.

Processing speed refers to ability to perform automatic tasks quickly, measurement of perceptual speed, speed of semantic processing, sustained attention under pressure as well as speed and efficiency of information processing. 


\section{POTENTIAL WEB BASED COGNITIVE EXERCISES IN REMEDIATION OF MIND (REMIND) PROGRAMME FOR SCHIZOPHRENIA RECOVERY}

Cognitive impairments in this domain have been regarded as a central feature [11] in schizophrenia among other domains which manifested slower speed of information processing [12], [10], [13].

\section{A. Computerized Cognitive Training}

Computer-based interventions provide an alternative to conventional approaches for $\mathrm{CR}$ which expanded the cognitive exercises selection range to some of the persistent cognitive challenges experienced by people with psychiatric illness. Hence, there are several acknowledged commercial companies which have potential in educational and rehabilitation strategies [11], [12].

The information processing of perceptual, visual, and motor cues is essential in evaluating cognitive software that should be coordinated to the participant's skill level. In addition to cognitive functioning, there are many aspects of participant skills that is considered when using computers to ensure that frustration towards lack of prerequisite skills in participant does not impede remediation of cognition [3]. Likewise, the cognitive remediation used the exercises in the training to offer new insights to the schizophrenia patients that differ between the current application and conventional approach that are most critical for generalization and the learning outcomes [15]. Significantly, the ultimate effects of brain plasticity through repetition in CR or interchangeably known as cognitive training are observed on the trained task, with transfer of skills and real life applications [2], [3].

Apparently, the use of a computer only may not predict the success of the CR. The advantages of computer-assisted $\mathrm{CR}$ are comprise of unlimited training possibilities, automatic reinforcement, multisensory presentation, objective recording of performance, standardized training tasks, intrinsic motivation, and so forth [18]. Hence, the IT application seems beneficial as a worldwide strategy in CR intervention due to its great evidence for substantial transfer effects upon treating cognitive deficits which is one of the most difficult and challenging area in the schizophrenia treatment. Therefore, this promising evidence based computerized treatment has a better prospect in a developing country like Malaysia as most of the healthcare premises in this country are technology and internet accessible [19]. Computerized Cognitive Remediation Project for Schizophrenia (CREPS) that was launched since 2005 at the Psychosocial Rehabilitation Unit, Department of Psychiatry, Hospital Universiti Sains Malaysia. The research project developed CREPS computerized cognitive remediation therapy (CRT) model which is fit to the Malaysian context [20]. The use of educational softwares and computer games as tools were to create an optimum learning environment as the learning process including Thinkin' Things 2 (Edmark), Factory Deluxe (Sunburst), Frogger 2 (Hasbro Interactive) and Logical Journey of the Zoombinis (Broderbund), and two developed game softwares, "Kitchen" and "Shop" games. These games were tailored to improve attention and immediate memory, working memory, planning skills and mental flexibility. Both games are available in English and Malay language.

However, the present ReMind programme is an early intervention that focusing on processing speeds in
In Malaysia, there is a pioneer CR programme namely,

ameliorating cognitive deficits while accelerating the performance in global cognition and functional outcomes. In this programme, the suitable existing software used in CREPS was counted in together with other potential targeted cognitive exercises. Hence, the potential computerized and web based cognitive exercises were identified to be part of tools in ReMind based on 5Cs outlined by [1] which consist of cognitive, client, computer, context and choice. In particular, the selection comprises of target deficits to be addressed is highlighted in cognitive. As for the client, the interests and level of functioning of the individual and the context of setting such as reading level, affective, motivational needs, suitable task content and relevance to treatment goal must be considered. Since the $\mathrm{CR}$ is a computerized training, thus the requirements and compatibility of the software and hardware are essential to look into besides the software in motivationally enhancing instructional technique of providing learner choices in adapting the activity which include multimedia format, printed output, difficulty level, automatically paced or specific menus, speed or contextualizing technique of the learning activity for generalization in real-world activity or only fantasy [3]

Hence, there are several companies and commercial products such as CIRCuiTS, Cogmed, Edmark (i.e., Thinkin' Things collection), Fit Brains, Lumosity, Posit Science (i.e., Brain HQ and Brain Fitness), SBTP Scientific Brain Training Pro (HAPPYneuron Pro), Sunburst Communications, and Fakt Software were stated to constitute a recommendation for CR intervention [1]. The appropriate features as remediation tools that best to align with the needs and treatment objective besides the transferability and improve specific skills in commercial products.

This is significantly due to the process of conducting the training was solely about the games. However the NEAR model has set the complete package where the cognitive training, neuropsychological principles, learning theory, neuroplasticity, and generalization through various bridging groups had been applied exclusively to proof the efficacy of cognitive remediation that undeniable improved the cognition and real life performance of schizophrenia at long term [22]. The gains from repetitive practice of the skills in multiple contexts are likely that generalization of cognition to functional capacity and daily tasks.

\section{B. Cognitive Software Task Analysis for ReMind}

The complication in many older CD version of training software such as not compatible to run well at newer computer and windows-based operating systems and hardware, the prominent program like Edmark product facing difficulty as they have not yet been replicated in webbased programs and become outdated to accommodate new platforms and systems. Thus, they are proliferating portable web-based programs that come with varieties and updates in packages besides application-based that available for tablets and smartphones. The interactivity with apps is based on 
screen touches instead of mouse clicks and typing, language requirements as well as budgetary considerations. There is a one-time fee for purchase of the program, whereas the web based packages like Lumosity and Fit Brains have monthly user fees but we took annually at affordable price for two years and allow multiple users per installation [1]. For the language, the stimuli that presented in written or auditory form to align with participant's needs and abilities were considered.

Therefore, the features and properties of cognitive exercises that maximizing therapeutic outcome in CR will be the priority in evaluating the program which comprise of degree of targeted deficits while addressing the learning needs, degree of cognitive skills training in generalization to real life functionality, and degree to which intrinsic motivation on improving cognitive health is engaged [23]. The task analysis was carried out to analyze each content of the games with several features and criteria for remediation. Although there were all in English, the wordings and instructions were checked to ensure it is suitable to Malaysian context and culture besides remediating criteria that matter. The adaptability of task, multimedia experience, and mediation by therapist were also considered in a computer task analysis.

The selection has been made in ReMind programme amongst the identified educational sources including commercial cognitive training available on the market to accommodate the demands in CR in young adults in FEP. In fact, this software task analysis was carried out in the ReMind cognitive exercises selection. Therefore, in making CR sustainability in Malaysia a success, a software library of cognitive exercises must be established progressively as suggested by [1], [3]. Having a range of web based cognitive games that targets cognitive skills and offers a variety of opportunities for contextualization and personalization according to ReMind objectives ensures the needs for real-world recovery can be met through processing speed domain.

The cognitive exercise task analysis towards available products has discovered 39 potential games before shortlisted to 26 to be used in ReMind programme which cover the core area of cognition (Working Memory, Auditory Memory, Visual Memory, Attention, Executive Function) through processing speed training in ReMind programme. There are from prominent educational resources of Lumosity, Fitbrains, brain training and existing software collection as recommended by NEAR and CREPS. Each exercise adapts its difficulty level to the user's ability.

\section{Cognitive Training Tools}

$\mathrm{CR}$ is widely known as a behavioral therapy that using computerized cognitive games as its tool to ameliorate the cognitive deficits in people with schizophrenia. Today, with the treatment and study design modified according to the program objectives as in ReMind, there is a crucial need to review all existing cognitive softwares after a decade it was established in Malaysia.

The barriers in the previous cognitive games consist of English proficiency and the foreign culturally context in most of the softwares besides the expensive price in bulk [20] and application of multimedia and graphics which already obsolete as compared to recent technology. Computer-based treatments for cognitive deficits have become progressively common and accessible. The impact an assortment of neurological states which relevant for developmental psychopathology is recognized to enhance cognitive function from the healthy to the neurologically impaired, across ages in both young and old yet beneficial to various populations [24].

Nevertheless, CR through its reliable computerized cognitive training which rigorously proven the effectiveness towards cognitive functioning as well as psychosocial outcomes may truly demonstrate beneficial in real life as it improves not only specific skills yet global domains as discovered in meta-analysis which demonstrates a small to moderate effect of cognitive rehabilitation on cognitive outcomes at posttreatment and follow-up assessment in individuals with a diagnosis of schizophrenia [25]. For the evaluation purpose, they have been given the opportunity to play and experience them, depending on the results of their cognitive assessment [3]. Significantly, the web-based cognitive games used in ReMind is expected to elucidate the great potential of processing speed training for $\mathrm{CR}$ development in Malaysia to enhance global cognition and functional outcomes in first episode of Schizophrenia.

\section{LUMOSITY}

There is several way to improve brains function [26] in the emerging science as the brain can intensely change and modify to become more efficient and effective in processing information, paying attention, remembering, thinking creatively, and solving novel problems [27]. This front-line science empowers people to exercise their brains and achieve their maximum performance through web-based software tools. In fact, Lumosity is a cognitive training suite, owned by Lumos Labs, Inc. which available through the web (in both browser and app versions) that offers engaging programs that can improve brain processes. It is designed to be customized by the user to specifically address five basic categories of cognitive processes such as Speed, Memory, Attention, Flexibility, and Problem Solving. The scientists at Lumos Labs work closely with game developers to create tasks that are both highly effective brain training and highly engaging games as it empirically proven through numerous studies conducted in cancer survivors, children with learning challenges, school preparedness, fluid intelligence training, and healthy adults. The effectiveness of Lumosity training in improving important aspects of cognition, across a variety of populations [26] was reported which the study [27] in children with leukemia or posterior brain tumors has demonstrated significant improvements in processing speed, visual memory and mental flexibility. Amazingly, Cancer survivors have benefited from reduced impact of chemo fog. These results demonstrate that training with the Lumosity tools can have wide-ranging and critical impacts in cognitive performance across the lifespan from school children to those interested in geriatric issues and from populations of normal, healthy participants to a variety 


\section{POTENTIAL WEB BASED COGNITIVE EXERCISES IN REMEDIATION OF MIND (REMIND) PROGRAMME FOR SCHIZOPHRENIA RECOVERY}

of patient groups regardless of one's starting point. Apparently, the results of these studies demonstrate

improvements in working memory, attention, executive function, and fluid intelligence, as well as improved performance in psychosocial functions and increased brain activity although not represent schizophrenia population.

Consequently, two relatively novel web based, Lumosity and Fit Brains have been chosen to be carried out in this study. As yet, there are currently no published results regarding efficacy of these CRTs in psychiatric cohorts [28]. In fact, a study via Lumosity as a tool in the internet-based CR intervention has initially proven the cognitive benefits and its feasibility in Clinical High Risk for Psychosis population although without control group as comparison [29]. There are games training speed of processing, memory, attention, mental flexibility, and problem solving. Although the Lumosity games are developed to train the five core areas of cognitive functions towards complementary functional domains to provide maximal benefit toward a specific goal, such as improving memory or getting better grades in school or workplace, these potential games could be tailored to early intervention in first episode of schizophrenia through ReMind program to enhance global cognitive domains effectively.

\section{E. FIT BRAINS}

Fit Brains is a web and app-based training package that provides engaging activities designed to improve basic cognitive functions. Intended for all users in schizophrenia which targets five general categories of cognitive functioning: Language, Problem Solving, Concentration, Memory, and Visual. Each exercise adapts its difficulty level to the user's ability. The concept of brain reserve is related to the brain plasticity. However, the Fit brains has already discontinued, and public are not to use it anymore due to financial issue.

These commercial brain trainings allow users to keep track of their progress and compare their performance to other users. Both games have also been used in other similar research in relation with cognitive rehabilitation. The method of delivery requires knowledge base such as domain specific knowledge, reading level, motivation as well as bridging group through generalization that allow participants to practice the gains in cognitive skill as part of building skill after the training.

The computerized game selection seems promising for ReMind programme which rigorously proven the treatment objectives towards global cognitive functioning as well as functional outcomes that truly demonstrate beneficial in real life as it improves not only specific skills yet across domains as discovered in meta-analysis which demonstrates a small to moderate effect of cognitive rehabilitation on cognitive outcomes at posttreatment and follow-up assessment in individuals with a diagnosis of schizophrenia [25]. Although the evidence remains scarce regarding the transferability of training to untrained domains of cognitive function, these variables are important cognitive functions, and have been shown to have significant impact on functional outcome in schizophrenia [29], [30] despite small sample size. Therefore, this study will ascertain the effectiveness of prospective cognitive games through Lumosity and Fitbrains for inclusive impact towards cognition and broad array of outcome measures in this population.

The advantage of computerized training is that it is provided on a computer that stimulates intrinsic motivation provided by the computer presentation as well as clear and fast feedback on past behavior. Thus, the learner have the control over the learning situation [32] besides the opportunity to take part in a social activity that led to improved self-esteem, yet learning. Thus, the NEAR model which highly proven the focus on educational principles and learning theory were evaluated to improve the learning environment in people with schizophrenia.

There are six tasks will be presented during each session [27] for each arm with 26 items identified for online cognitive training. Each participant was not provided with any user ID and password to log into any website of Lumosity or Fitbrains from their home personal computer unless they subscribe on their own. The system was registered for the research administrator only. Thus, no personal information was recorded and stored. Participants were given instructions and demonstration about the learning rules. Participants were asked to do the assigned exercises that can be accessed from the computer, tablet, and laptop according to treatment plan upon commencement of session.

Developing a custom-made local CR software or website was interesting but the high cost incurred to develop such an established commercial website was the constraint although we have the computer graphic developer and designers for that. Therefore, in response to growing needs for appropriate cognitive training materials in a treatment for specific group of population in ReMind programme, a numerous list of products available for $\mathrm{CR}$ were evaluated to identify the cognitive training exercises besides approaches, strategies and procedures that have been determined prior to the software task analysis for the implementation of CR.

\section{METHODOLOGY}

Supremely, developing games software is difficult and expensive. Fortunately, this study has been awarded with a research grant which was secured to identify and subscribe the suitable commercial web based cognitive exercises and other necessity related to ReMind programme. Seemingly, the software was analyzed in stages based on the task analysis and the criteria that should adhere to guidelines provided by [14], [32]. The final products selected were then pilot tested on a few patients and comments were gathered through focus group discussion to explore the experience towards potential of the games. In this present study, the final products and findings of FGDs were discussed in detail.

The existing software for CRT and potential cognitive exercises have therefore been explored by evaluating them based on theoretical, evidence-based practice, and remediating criteria for the usefulness and suitability of exercises for participants and ReMind treatment objectives. 
A software task analysis (STA) of potential games and a brief interview questions was adopted as the method of the needs analysis prior to intervention execution [1]. In fact, task analysis is a rational-empirical approach developed by cognitive psychologists for studying how people carry out problem-solving tasks and successfully resolve emotional processing difficulties in therapy. The evaluation of the STA findings through a focus group discussion (FGD) to the participants who were experienced the training contents through a brief questionnaire that relate to the potential, strengths, weaknesses and difficulties of the cognitive exercises for ReMind programme. The overall findings of existing studies of CR indicate that adequate and appropriate training is a key to any success particularly in early intervention which was slightly different from the general domains of cognitive functioning. Accordingly, the specific domain of cognitive exercises have been chosen as the key ingredients [34] of the ReMind programme in FEP population for better outcomes of global cognition and functional outcomes [33].

Hence, the selection has been made in ReMind programme amongst the commercial educational or cognitive training available on the market to accommodate the demands in CR

in young adults in FEP. In accomplishing this becomes reality, a software analysis towards potential cognitive games was conducted based on NEAR model and learning principles to ensure the applicability to CR. The task analysis of the cognitive game is based on a few theories and principles which comprise of motivation (intrinsic and extrinsic), depth of engagement, opportunities for selfcontextualization, learner control or choice, opportunities for practice and personalization according to educational principles. In addition, the learner control or choice to certify adaptively hierarchical in the cognitive exercises; simple stimuli with difficulty level, longer time limits, cued or scaffolded items, illustrations or explanations of competitive correct responses were also taken into consideration in evaluating software.

The intervention took them 15 sessions of processing speed training with six tasks presented during each session followed with two bridging groups within the sessions. The treatment was designed to address the needs in focus global domains of cognitive functioning and functional outcome through targeted processing speed with the aim to enhance functionality and cognitive recovery. As the participant's performance improved, difficulty level was increased especially for more complex stimuli, shorter time limits, provide hints or explanations with repetition with at least three times allowed.

The focus group (FGD) then was assembled to explore participants' response through ReMind programme particularly the potential cognitive exercises they experienced. Bridging group interviews were held with the CR intervention group at two hospitals in Klang valley, Malaysia which involved in the study from November 10 , 2016 to December 19, 2017. Each group was made up of three to four participants of FEP. Focus groups of no more than eight participants were a recommendation echoed by several practitioners. Thus, triads and mini-groups were perceived competence, multisensory presentation,

implemented as alternatives for generating ideas as there are well-suited to obtaining reactions to product stimuli and generating refinements. The objectives of the FGDs were to explore the potential cognitive games of several other sources as to complement the previous task analysis to be replicated in the $\mathrm{CR}$ actual trial. These FGDs were conducted within 20-30 minutes of duration.

\section{RESULTS AND DISCUSSION}

Cognitive exercises have been used to remediate cognitive impairments as therapeutic interventions for neuropsychiatric illness, and to explore mechanisms of experience in the cognitive rehabilitation. The findings revealed that there is evidence that computerized games improved cognitive functioning and psychosocial. The webbased cognitive exercises are useful as neuropsychological educational tools for remediation. While demand in this area is still crucial particularly in the Malaysian context, there are interesting results that encourage further work in this field, and hold promise for utilizing this technology as a powerful therapeutic and experimental tool.

Since the potential ReMind cognitive exercises have been analyzed through STA, the next phase has then anticipated those games to be evaluated in a pilot study and FGD for its feasibility. As a result, there are 26 shortlisted potential games included in the ReMind module to be used in that study as shown in table 1 . The selection of web based cognitive games were the main findings which they gave their views on how they perceived by those exercises and learning style involved throughout the intervention. Some participants find difficulties in cognitive training as challenges they have yet to face as being particularly never frustrating them.

Improvements in the patients' cognitive processing skills were measurable by the indication of trials and time taken to complete each game. Yet, the difficulty and complexity would be higher as they are able to get through the upper levels. This helps participants to keep their attention and creativity to complete the task given through cognitive training. On the other hand, the frustration tolerance in participants to keep trying from one level to another indicated the motivation towards these great cognitive games before it gets challenging. After the intervention a discussion through focus group conducted to 22 patients with FEP using these computerized exercises, $84 \%$ found it interesting to learn and $16 \%$ found it challenging. While in a simple survey done to 30 patients during pilot study (patients' diary) reported, 75\% found it interesting to learn and $25 \%$ found it challenging.

The games selection at intermediate level is based on their requirement and training capabilities in processing speed, attention and to some degree memory in Highway Hazard.

In fact, processing speed is an important cognitive function and has been considered as the core deficit in mediating other higher cognitive functions like problem solving and memory [10], [36] as in Train of Thought and 


\section{POTENTIAL WEB BASED COGNITIVE EXERCISES IN REMEDIATION OF MIND (REMIND) PROGRAMME FOR SCHIZOPHRENIA RECOVERY}

Pet Detective.

The participants' severity in processing speed were given different level of cognitive training according to their own pace, depending on their interest in the games selection and how much remediation is required in the cognitive deficit. They were asked to spend quite some time at processing speed games range (Splitting Seeds, River Ranger) which require a moderate speed at controlling the mouse cursor, before moving on to a faster paced yet advanced games like Highway Hazard, Quick blocks and Paint Drop.

Other than the stated above, there are several advanced games which identified challenging to participants from the
FGDs such as Stocktopus (from Thinkin' Things 3) and Zoombinis. However, a few more software which classified as challenging could not be used completely in this study as the CDs did not work accordingly due to its condition. Therefore, a good game like where in the World is Carmen Sandiego were unable to be used in ReMind and has been replaced with other challenging games like SimCity, Chalkboard Challenge, Brain Shift, Brain Shift Overdrive, Disillusion, Organic Order, Speed Match, Spatial Speed Match, Speed Match Overdrive, and Sequence Numbers and Alphabets. Afterall, the total games were finalized to be used in ReMind programme are as in Table I.

Table- I: Potential cognitive exercises in ReMind programme

\begin{tabular}{|c|c|c|c|}
\hline Games & Software/ Apps & $\begin{array}{c}\text { Target Predictor Variables/ Targeted Cognitive } \\
\text { Deficits } \\
\end{array}$ & Method of Delivery \\
\hline Highway Hazards & Lumosity & $\begin{array}{l}\text { Processing Speed and Attention } \\
\end{array}$ & \\
\hline Splitting seeds & Lumosity & Problem solving, quantitative reasoning & \\
\hline River Ranger & Lumosity & Executive function, problem solving and planning & \\
\hline Penguin pursuit & Lumosity & $\begin{array}{c}\text { Spatial orientation, sense of direction and aware of } \\
\text { surrounding. }\end{array}$ & \multirow{23}{*}{$\begin{array}{l}\text { Required domain } \\
\text { specific knowledge } \\
\text { based and reading } \\
\text { level: SPM and } \\
\text { above } \\
\text { Requirements of } \\
\text { the activity: } \\
\text { Intrinsic } \\
\text { Motivation } \\
\text { Metacognitive } \\
\text { Bridging Group: } \\
\text { Participants will be } \\
\text { encouraged to } \\
\text { participate and practice } \\
\text { the cognitive skill after } \\
\text { the training }\end{array}$} \\
\hline 5. Speed Match & Lumosity & $\begin{array}{c}\text { Processing Speed \& Reaction Time/ Visual Motor } \\
\text { Response and Incidental Learning }\end{array}$ & \\
\hline 6. Spatial Speed Match & Lumosity & $\begin{array}{c}\text { Processing Speed \& Reaction Time/ Visual Motor } \\
\text { Response and Incidental Learning }\end{array}$ & \\
\hline $\begin{array}{lll}\text { 7. } & \begin{array}{l}\text { Speed } \\
\text { Overdrive }\end{array} & \text { Match } \\
\end{array}$ & Lumosity & $\begin{array}{c}\text { Processing Speed \& Reaction Time/ Visual Motor } \\
\text { Response and Incidental Learning }\end{array}$ & \\
\hline 8. $\quad$ Speed Sort & Fit Brains & Processing Speed & \\
\hline Quick blocks & Fit Brains & Processing Speed & \\
\hline 10. Sequence Numbers & Brain Training & Divided Attention, Memory and Processing Speed & \\
\hline 11. Random Numbers & Brain Training & Divided Attention, Memory and Processing Speed & \\
\hline 12. Sequence Alphabets & Brain Training & Divided Attention, Memory and Processing Speed & \\
\hline 13. Train of thought & Lumosity & $\begin{array}{l}\text { Executive functions, Divided Attention and reaction } \\
\text { time }\end{array}$ & \\
\hline 14. Raindrops & Lumosity & $\begin{array}{c}\text { Numerical calculation, Attention, Concentration, } \\
\text { Forward Planning, Processing Speed }\end{array}$ & \\
\hline $\begin{array}{ll}\text { 15. } & \begin{array}{l}\text { Chalkboard } \\
\text { Challenge }\end{array} \\
\end{array}$ & Lumosity & Problem solving, quantitative reasoning & \\
\hline 16. Pet Detective & Lumosity & Executive function, problem solving and planning & \\
\hline 17. Brain Shift & Lumosity & Flexibility, Task Switching & \\
\hline $\begin{array}{lll}\text { 18. } & \begin{array}{l}\text { Brain } \\
\text { Overdrive }\end{array} \\
\end{array}$ & Lumosity & Flexibility, Task Switching & \\
\hline 19. Color Match & Lumosity & Flexibility, Response Inhibition & \\
\hline 20. Disillusion & Lumosity & Flexibility, Task Switching & \\
\hline 21. Organic Order & Lumosity & Logical Reasoning and Problem Solving & \\
\hline 22. Ebb and Flow & Lumosity & $\begin{array}{l}\text { Flexibility, Task Switching } \\
\end{array}$ & \\
\hline 23. Stocktopus & $\begin{array}{l}\text { Thinkin' Things } \\
3\end{array}$ & $\begin{array}{l}\text { Working Memory, Forward Planning, Deductive } \\
\text { reasoning, and categorisation of information in order to } \\
\text { solve problem. }\end{array}$ & \\
\hline $\begin{array}{l}\text { 24. Zoombinis Logical } \\
\text { Journey }\end{array}$ & Zoombinis & $\begin{array}{l}\text { Attention, Incidental Learning, Forward Planning, } \\
\text { Processing Speed, Problem Solving }\end{array}$ & \\
\hline 25. Shop Game & CREPS games & Planning & \\
\hline $\begin{array}{l}\text { 26. } \begin{array}{l}\text { Diner Dash/ Hotel } \\
\text { Dash }\end{array} \\
\end{array}$ & CREPS games & Planning, Reaction Time \& Processing Speed & \\
\hline
\end{tabular}

*Highlighted row: Discontinued software from Fitbrains All levels provided immediate feedback regarding score and accuracy of responses at minimum of $80 \%$. Thus, the games should offer a range of tasks that reflects an understanding of cognition on a hierarchy which choices about the sequence of presentation in hierarchical order at patient's pace. Furthermore, the repetition of each task given with at least three times of training to reach the minimum accuracy was indeed not burdening the participants as they could constantly remain attentive and passionate even though at the advanced level. In view of that, the repetition strategy as in correct responses would produce competency in people with FEP for the functionality.

\section{F. Cognitive Games Strength and Difficulty}

The selection of web based cognitive games were the main findings which they gave their views on how they are perceived by those exercises and learning style involved throughout the intervention. Some participants find difficulties in cognitive training as challenges they have yet to face as being particularly never frustrating them.

Meanwhile, ten cognitive games were selected based on challenge and strength after the same data obtained which no newer data recorded as the data is saturated. Pet Detective $(n=9)$, was chosen as cognitive games challenge followed by Penguin Pursuit $\quad(n=9)$, Highway Hazards $(n=9)$, Speed Match ( $n=7)$, River Ranger $(n=7)$, Disillusion 
$(n=6)$, Brain Shift $(n=6)$, Train of Thought $(n=6)$, Zoombinis $(\mathrm{n}=5)$, and Rain drops $(\mathrm{n}=5)$. Meanwhile, Highway Hazards $(n=14)$, Splitting Seeds $(n=10)$, Train of Thought $(n=8)$, River Ranger $(n=7)$, and Brain Shift $(n=7)$ were five most preferred as there are less challenging as displayed in Fig. 1.
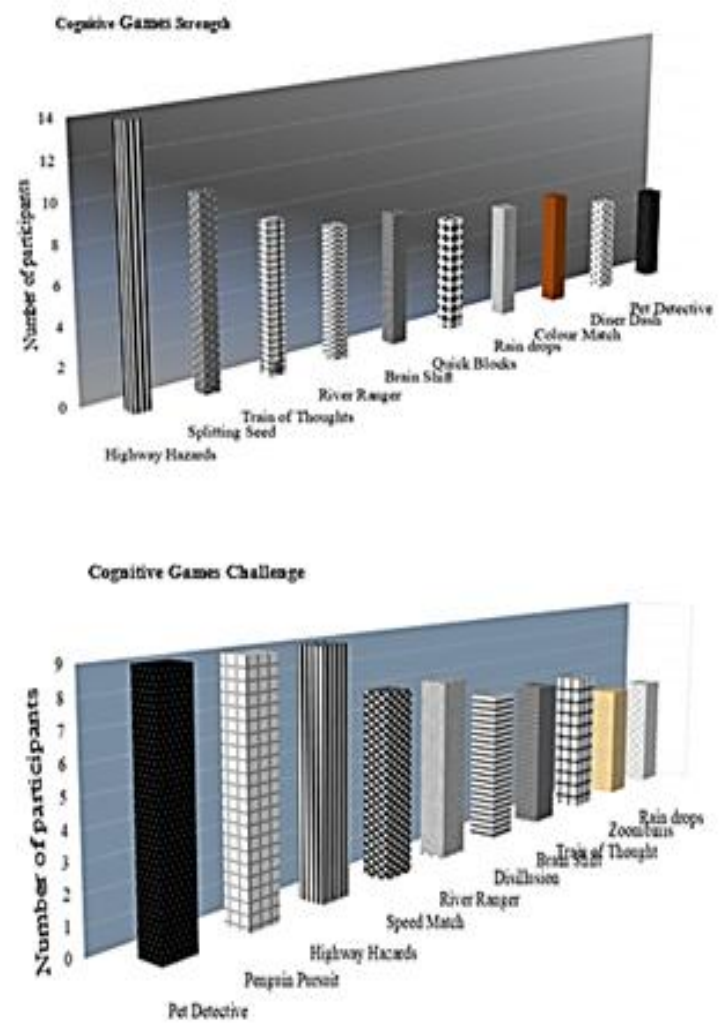

Fig. 1. ReMind Computerised Cognitive Exercises

\section{G. Training Gains and Learning Process}

The following focus group discussion from five groups of has described the games pattern of thoughts as derived by the codes.

Highway Hazards: “...main kereta lumba. Aaa.. kena elak halangan dan uji ketangkasan dan kecepatan. Kena fikir selari dengan pandangan/reaction." Participant Group 1

"...like a racing car. Aaa.. need to avoid the hurdle \& test your efficiency. I also have to think in line with reaction." Participant Group 2A

Pet Detective: “...guna kemahiran buat keputusan dengan tepat dengan sumber minyak yang terhad perlu pandai cukupkan, sebab nak kena hantar pets." Participant Group 4

“...use problem solving skills with limited fuel, know how to get it to send the pets." 2B

Train of Thought: “... Melatih pembahagian fokus, processing speed, planning, and memory.

".. it trains us in dividing attention, processing speed, planning, and memory" Participant Group 3

The participants viewed that the main strengths of the programme as interesting and it improves cognition such as memory, attention, processing speed and problem-solving skills for patients with schizophrenia. The other group viewed that the strengths are the use of IT and requires minimal infrastructure, and patients can learn to use computers as well. Isolated views included that "it is easy to train therapists", "patients get a one to one attention", "it is evidence based", "it improves patients' confidence in themselves" and "treatment can be tailored to patients' needs and capability".

Overall, the exploratory findings of potential cognitive games from the FGD interview transcripts produced a clear interpretation of potential cognitive games for the targeted processing speed, as the participants had attached their own meaning to each game which was more relevant to their experiences towards cognitive process which the themes were created as displayed through framework analysis in figure 2 .

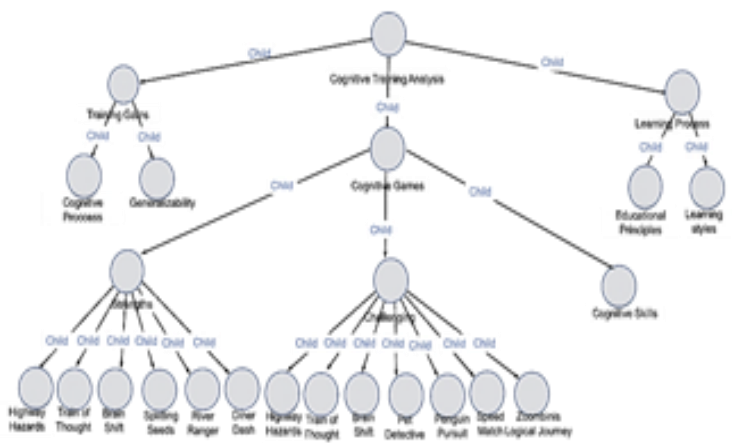

Fig. 2. Framework Analysis Map of ReMind Exercises

Three main themes include training gains, cognitive exercises strength and challenge, and learning process were confirmed and concluded the exploration towards potential computerized games to be used in ReMind program.

Approaches to CR vary depending on the extent to which adopting restorative and compensatory techniques. The use of drill and practice exercises that aim to restore cognitive functions is based on evidence for lifelong neuroplasticity and supported by evidence for functional change with targeted behavioral intervention [9]. Furthermore, patient's motivation is found to be an important factor for rehabilitation success [38] despite with computerized training plus the therapist-guided instruction to link training exercises to everyday life in ensuring the fidelity of intervention through principles of learning.

\section{CONCLUSION}

The ReMind programme is an initiative to value added of CR service after ground-breaking the first computerized CR in Malaysia a decade ago. This early intervention program is targeting processing speed to accelerate the cognitive performance and functional outcomes in young adults of first episode psychosis using web based cognitive training. The promising tools have proven to enlighten schizophrenia patients with the advanced technology in facilitating the cognitive recovery process effectively. The use of this cognitive game selection should be expanded not solely for rehabilitation but also in healthy cognitive health to ensure the benefits could be optimized extensively. The development of the web based cognitive exercises according 
to local cultural context in future will be more beneficial particularly to optimize patient's recovery yet valuable in elevating the psychiatric rehabilitation equipment in Malaysia.

\section{ACKNOWLEDGMENT}

The present study was provided by the Research Support Grant (GGP-2017-062) from Universiti Kebangsaan Malaysia (UKM)

\section{REFERENCES}

1. A. Medalia, T. Herlands, A. Saperstein, and N. Revheim, Cognitive remediation for psychological disorders: Therapist guide. United States of America: Oxford University Press, 2018.

2. A. Medalia, A. T. Beck, and P. M. Grant, "Cognitive therapies for psychosis: Advances and challenges," Schizophr. Res., 2019, pp.1-2, 2018.

3. A. Medalia, N. Revheim, and T. Herlands, Cognitive remediation for psychological disorders: Therapist guide. The United States of America: Oxford University Press, 2009.

4. R. S. C. Lee, M. Redoblado-Hodge, S. L. Naismith, D. F. Hermens, M. A. Porter, and I. B. Hickie, "Cognitive remediation improves memory and psychosocial functioning in first-episode psychiatric out-patients," Psychol. Med., vol. 43, no. 2013, pp. 1161-1173, 2012.

5. E. W. Twamley, D. V. Jeste, and A. S. Bellack, "A review of cognitive training in schizophrenia," Schizophr. Bull., vol. 29, no. 2, pp. 359-382, 2003.

6. G. Sartory, C. Zorn, G. Groetzinger, and K. Windgassen, "Computerized cognitive remediation improves verbal learning and processing speed in schizophrenia," Schizophr. Res., vol. 75, no. 2-3, pp. 219-223, 2005.

7. A. M. Owen, A. Hampshire, J. A. Grahn, R. Stenton, S. Dajani, A. S. Burns, R. J. Howard, and C. G. Ballard, "Putting brain training to the test," Nature, vol. 465, no. 7299, pp. 775-8, 2010.

8. R. Penadés and R. Catalán, "Cognitive Remediation Therapy (CRT): Improving neurocognition and functioning in schizophrenia," in Schizophrenia in the 21st Century, T. H. J. Burne, Ed. London: IntechOpen, 2012, pp. 69-86.

9. R. I. Mesholam-Gately, A. J. Giuliano, K. P. Goff, S. V. Faraone, and L. J. Seidman, "Neurocognition in firstepisode schizophrenia: A meta-analytic review.," Neuropsychology, vol. 23, no. 3, pp. 315-336, 2009.

10. J. M. Rodríguez-Sánchez, B. Crespo-Facorro, C. González-Blanch, R. Perez-Iglesias, and J. L. VázquezBarquero, "Cognitive dysfunction in first-episode psychosis: The processing speed hypothesis.," Br. J. Psychiatry. Suppl., vol. 51, pp. 107-110, 2007

11. D. Dickinson and P. D. Harvey, "Systemic hypotheses for generalized cognitive deficits in schizophrenia: A new take on an old problem," Schizophr. Bull., vol. 35, no. 2, pp. 403-414, 2009.

12. D. Dickinson, M. E. Ramsey, and J. M. Gold, "Overlooking the obvious," Arch. Gen. Psychiatry, vol. 64, pp. 532-542, 2007.

13. R. Andersen et al., "The influence of impaired processing speed on cognition in first-episode antipsychotic-naïve schizophrenic patients," Eur. Psychiatry, vol. 28, no. 6, pp. 332-339, 2012.

14. S. Zickefoose, K. Hux, J. Brown, and K. Wulf, "Let the games begin: A preliminary study using Attention Process Training-3 and Lumosity TM brain games to remediate attention deficits following traumatic brain injury," Brain Inj., vol. 27, no. 6, pp. 707-716, 2013.
15. S. Raffard, M. C. Gely-Nargeot, D. Capdevielle, S Bayard, and J. P. Boulenger, "Learning potential and cognitive remediation in schizophrenia," Encephale., vol. 35, pp. 353-360, 2009.

16. R. Penadés, N. Pujol, R. Catalán, G. Massana, G. Rametti, C. García-Rizo, N. Bargalló, C. Gastó, M. Bernardo, and C. Junqué, "Brain effects of cognitive remediation therapy in schizophrenia: A structural and functional neuroimaging study," Biol. Psychiatry, vol. 73, no. 10, pp. 1015-1023, 2013.

17. S. Fisher, C. Holland, M. M. Merzenich, and S. Vinogradov, "Using neuroplasticity-based auditory training to improve verbal memory in schizophrenia," Am. J. Psychiatry, vol. 166, no. 7, pp. 805-811, 2009.

18. O. Grynszpan, S. Perbal, A. Pelissolo, P. Fossati, R. Jouvent, S. Dubal, and F. Perez-Diaz, "Efficacy and specificity of computer-assisted cognitive remediation in schizophrenia: A meta-analytical study," Psychol. Med., vol. 41, no. 1, pp. 163-173, 2010.

19. Muhammad Najib Mohamad Alwi, "Cognitive remediation for schizophrenia: New focus for Malaysian psychiatry?" Malaysian J. Psychiatry, vol. 15, no. 2, pp. $11-7,2006$

20. M. N. M. Alwi, H. C. Ismail, A. Harris, and P. Boyce, "Prospect of computerised cognitive remediation therapy in Malaysia: Results of a pilot study in Kota Bharu, Kelantan," Malaysian J. Psychiatry, vol. 18, no. 1, pp. 14, 2009.

21. A. Medalia, "Cognitive remediation for psychiatric patients: Improving functional outcomes for patients with schizophrenia," Psychiatric. Times, vol. 26, no. 3, pp. 23-25, 2009.

22. K. H. Nuechterlein, J. Ventura, S. C. McEwen, D. Gretchen-Doorly, S. Vinogradov, and K. L. Subotnik, "Enhancing cognitive training through aerobic exercise after a first schizophrenia episode: Theoretical conception and pilot study," Schizophrenia Bulletin, vol. 42, no. suppl_1,2016, pp. S44-S52.

23. A. Medalia and A. Saperstein, "Does cognitive remediation for schizophrenia improve functional outcomes?" Curr Opin Psychiatry, vol. 26, no. 2, pp. $151-157,2013$.

24. S. Rabipour and A. Raz, "Training the brain: Fact and fad in cognitive and behavioral remediation," Brain Cogn., vol. 79, no. 2, pp. 159-179, 2012.

25. T. Wykes, H. Vyv, C. Cellard, S. R. Mcgurk, and P. Czobor, "A meta-analysis of cognitive remediation for schizophrenia: Methodology and effect sizes," American Journal of Psychiatry, vol. 168, no. 5, pp. 472-485, 2011.

26. J. Hardy and M. Scanlon, The science behind lumosity. California: Lumos Labs, 2009.

27. S. R. Kesler, N. J. Lacayo, and B. Jo, "A pilot study on an online cognitive rehabilitation program for executive function skills in children with cancer-related brain injury," Brain Inj., vol. 25, no. 1, pp. 101-112, 2012.

28. D. Piskulic, M. Barbato, L. Liu, and J. Addington, "Pilot study of cognitive remediation therapy on cognition in young people at clinical high risk of psychosis," Psychiatry Res., vol. 225, no. 1-2, pp. 93-98, 2015.

29. C. I. Hooker, E. E. Carol, T. J. Eisenstein, H. Yin, S. H. Lincoln, L. M. Tully, D. Dodell-Feder, M. Nahum, M. S. Keshavan, and L. J. Seidman, "A pilot study of cognitive training in clinical high risk for psychosis: Initial evidence of cognitive benefit," Schizophrenia Research, vol. 157, pp. 314-316, 2015. 
30. C. R. Bowie, W. W. Leung, A. Reichenberg, M. M. McClure, T. L. Patterson, R. K. Heaton, and P. D Harvey, "Predicting schizophrenia patients' real-world behavior with specific neuropsychological and functional capacity measures," Biol. Psychiatry, vol. 63, pp. 505511,2008

31. M. Cella, C. Reeder, and T. Wykes, "Lessons learnt? The importance of metacognition and its implications for cognitive remediation in schizophrenia," Front. Psychol., vol. 6, pp. 1-9, 2015.

32. T. Wykes and M. Van Der Gaag, "Is it time to develop a new cognitive therapy for psychosis - Cognitive remediation therapy (CRT)?" Clin. Psychol. Rev., vol. 21, no. 8, pp. 1227-1256, 2001.

33. A. Medalia and B. Freilich, "The Neuropsychological Educational Approach to Cognitive Remediation (NEAR) Model: Practice principles and outcome studies," Am. J. Psychiatr. Rehabil., vol. 11, no. 2, pp. 123-143, 2008

34. N. Franck, C. Duboc, C. Sundby, I. Amado, T. Wykes, C. Demily, C. Launay, V. L. Roy, P. Bloch, D. Willard, and A. Todd, "Specific vs general cognitive remediation for executive functioning in schizophrenia: A multicenter randomized trial," Schizophr. Res., vol. 147, no. 1, pp. 68-74, 2013.

35. D. L. Penn, E. J. Waldheter, D. O. Perkins, K. T. Mueser and J. a Lieberman, "Psychosocial treatment for firstepisode psychosis: A research update," Am J Psychiatry, vol. 162, no. 12, pp. 2220-2232, 2005.

36. J. Addington, B. L. Brooks, and D. Addington, "Cognitive functioning in first episode psychosis: Initial presentation," Schizophr. Res., vol. 62, no. 1-2, pp. 5964, 2003.

37. N. Ojeda, J. Peña, E. Bengoetxea, R. Segarra, P. M. Sánchez, E. Elizagárate, J. García, J. I. Eguiluz, J. Ezcurra, and M. Gutiérrez, "P03-122 - Cognitive rehabilitation in executive functioning and processing speed in schizophrenia and first-episode psychosis," Eur. Psychiatry, vol. 25, no. Supplement 1, pp. 1102, 2010.

38. A. Shapi'i, N. A. Mat Zin, and A. M. Elaklouk, "A game system for cognitive rehabilitation," Biomed Res. Int., vol. 2015 , pp. 1-7, 2015.

\section{AUTHORS PROFILE}

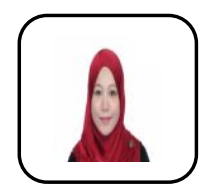

Naniyati Shuib Clinical Psychologist, M (Clinical Psychology), Faculty of Health Sciences, Universiti Kebangsaan Malaysia.

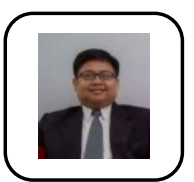

Dr. Mahadir Ahmad Senior Lecturer/ Consultan Clinical Psychologist, Faculty of Health Sciences, Universiti Kebangsaan Malaysia.

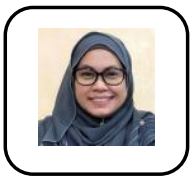

Assoc. Prof. Dr. Zubaidah Jamil Osman Senio Lecturer/ Consultant Clinical Psychologist, Faculty of Allied Health Sciences, Cyberjaya University College of Medical Sciences, Malaysia.

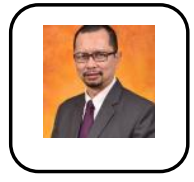

Prof. Dr. Muhammad Najib Mohamad Alwi Senior Lecturer/ Consultant Psychiatrist, International Medical School, Management and Science University, Malaysia. 